\section{O PROCESSO DE CRIAÇÃO DE UM SOFTWARE EDUCACIONAL PARA O ENSINO E APRENDIZAGEM DE QUÍMICA}

The process of creation of an educational software for teaching chemistry learning

El proceso de creación de un software educacional para la enseñanza aprendizaje de química

\section{Resumo}

Este artigo apresenta o processo de desenvolvimento de um software educacional voltado para o conteúdo químico de balanceamento de equações. O software foi desenvolvido considerando as características de um jogo digital no sentido de associar abordagem conceitual, tecnologias e o contexto lúdico. São apresentadas todas as etapas de criação e o produto final evidenciando-se as principais dificuldades encontradas nesse processo. São discutidas também as características do jogo digital e os principais aspectos que permeiam o fazer docente quando se buscam novos caminhos de abordagem em sala de aula. $\mathrm{O}$ jogo desenvolvido "BalanceQuímico" foi aplicado aos graduandos do curso de Licenciatura em Química da Universidade Estadual de Goiás caracterizando algumas perspectivas didáticas que resultam do entrelace entre os elementos lúdicos, tecnológicos e conceituais.

Palavras-Chave: 1: Ensino e aprendizagem de Química; 2: Software educacional; 3: "BalanceQuímico".

\begin{abstract}
This article presents the process of developing an educational software for the chemical content of equation balancing. The software was developed considering the characteristics of a digital game in the sense of associating conceptual approach, technologies and the ludic context. All the stages of creation and the final product are presented, evidencing the main difficulties encountered in that process. Also discussed are the characteristics of the digital game and the main aspects that permeate the teaching process when looking for new ways of approach in the classroom. The game "BalanceQuímico" was applied to graduates of the degree in Chemistry of the State University of Goiás characterizing some didactic perspectives that result from the interplay between the ludic, technological and conceptual elements.
\end{abstract}

Keywords: 1: Teaching Chemistry Learning ; 2: Educational Software ; 3: "BalanceQuímico".

\section{Resumen}

Este artículo presenta el proceso de desarrollo de un software educativo orientado al contenido químico de equilibrio de ecuaciones. El software fue desarrollado considerando las características de un juego digital en el sentido de asociar enfoque conceptual, tecnologías y el contexto lúdico. Se presentan todas las etapas de creación y el producto final evidenciando las principales dificultades encontradas en ese proceso. Se discuten también las características del juego digital y los principales aspectos que permean la acción docente al buscar nuevos enfoques en el aula. El juego "BalanceQuímico" fue aplicado a los graduandos del curso de Licenciatura en Química de la Universidad Estadual de Goiás caracterizando algunas perspectivas didácticas que resultan del entrelazado entre los elementos lúdicos, tecnológicos y conceptuales.

Palabras clave: 1: Enseñanza aprendizaje de Química; 2: Software educativo; 3 "BalanceQuímico".

\section{AUTORES:}

GISLANE S. N. BARRETO'

ORCID 0000-0001-8624-0993

${ }^{1}$ Profa. Da Educação Básica de Goiás

JANAINA LOPES XAVIER ${ }^{2}$

ORCID 0000-0001-7118-1185

${ }^{2}$ Profa. da Educação

Básica de Goiás

JOSÉ DIVINO DOS

SANTOS 3

ORCID 0000-0002-9272-414

3Universidade

Estadual de Goiás

(UEG)

NYUARA A. S. MESQUITA ${ }^{4}$

ORCID 0000-0003-2410-6304

${ }^{4}$ Universidade Federal de Goiás (UFG)

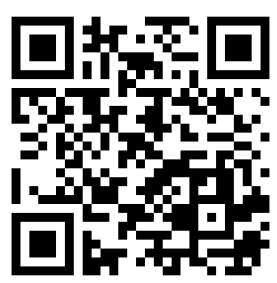

Para citar este artigo:

BARRETO, G. S N.; XAVIER, J. L.; SANTOS, J. D.; MESQUITA, N. A. S. O processo de criação de um software educacional para o processo de ensino e aprendizagem de química.

Revista Eletrônica Ludus Scientiae, Foz do Iguaçu, v. 01, n. 02, p. 90-106, ago./dez. 2017. 


\section{INTRODUÇÃO}

O acelerado desenvolvimento tecnológico reflete hoje no posicionamento do professor que, aos poucos, tenta se adaptar a uma nova realidade com a finalidade de aprimorar o ensino e, consequentemente, proporcionar qualidade no processo de ensino e aprendizagem (NUNES; SANTOS, 2013). A introdução das novas tecnologias no contexto escolar, como instrumentos potencializadores do processo de ensino e aprendizagem, vem ao encontro dos interesses dos estudantes, o que pode propiciar a apropriação de conteúdos abstratos, como é o caso do acerto dos coeficientes estequiométricos das reações químicas.

Diante desse escopo, softwares educacionais com propostas pedagógicas relacionadas a jogos ou conteúdos específicos podem ser encontrados facilmente na internet. Dessa forma, o que hoje é considerado corriqueiro para o aluno, como o uso de internet, celulares e computador, pode-se transformar instrumento de ensino e aprendizagem, como a abordagem didática por meio da utilização de softwares educacionais (AULER; DELIZOICOV, 2006).

Diversos estudos relatam a importância da utilização desses recursos computacionais, softwares, como ferramenta essencial e indispensável na construção do conhecimento (MEDEIROS, 2013). Segundo Carraher (1992) o sucesso de um software em promover a aprendizagem depende da integração deste no currículo e nas atividades de sala de aula. No contexto do ensino de Química, o uso da informática, associado às simulações virtuais, oferece estratégias de interação aos usuários, tornando o ensino interessante e compreensível (SOUZA et al., 2005).

O estudo aqui apresentado faz parte de um projeto de pesquisa realizado no Mestrado Profissional em Ensino de Ciências, que teve como um dos objetivos específicos o desenvolvimento de um software educacional aplicável ao ensino de Química e sua aplicação aso graduandos do curso Licenciatura em Química da Universidade Estadual de Goiás. Sendo assim, este artigo objetiva mostrar os caminhos de elaboração de softwares educacionais pensados para o processo de ensino e aprendizagem de Química e consiste em um relato detalhado da elaboração e desenvolvimento do software educacional e algumas considerações feitas pelos graduandos. O software foi desenvolvido a partir da linguagem de programação Python por uma professora de química (a pesquisadora) buscando inserir características lúdicas que o configurassem como jogo. Ressaltamos que a elaboração desse software foi pensada para o contexto da formação de professores de química visando mobilizar a atenção para as relações entre os aspectos lúdicos e tecnológicos presentes no material.

O texto encontra-se dividido em três partes. A primeira apresenta as perspectivas teóricas assumidas em relação à tecnologia, ludicidade e ensino de Química e também traz aspectos relacionados ao conteúdo que envolve o ensino do acerto dos coeficientes estequiométricos e suas dificuldades. Na segunda etapa, descrevemos o processo metodológico da concepção e implementação do software "BalanceQuimico". A última etapa consiste na implementação do software, que é definida como: elaboração de um protótipo e o desenvolvimento da aplicação e também a aplicação do software no formato de um jogo digital

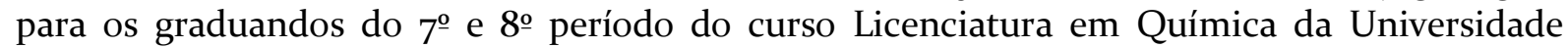
Estadual de Goiás.

\section{Tecnologia, ludicidade e ensino de Química}

O processo de ensino e aprendizagem na área da Química vem enfrentado alguns problemas e, consequentemente, ganhando espaço nas discussões acadêmicas. De acordo com Nunes e Santos (2013) os professores reclamam que não conseguem manter a atenção dos seus alunos e que estes não mostram interesse pelos conteúdos. Os alunos alegam que as aulas de Química são monótonas, complexas, decorativas e que não veem motivos para aprendê-la. 
Diante a todas as dificuldades relatadas, a inserção das tecnologias no contexto do ensino de Química tem sido um elemento novo de acordo com diversos autores. Giordan (2013) afirma que as Tecnologias da Informação e Comunicação (TIC) se apresentam como novos recursos que facilitam, motivam, atualizam e contribuem com o processo de ensino e aprendizagem de Ciências. O autor complementa que os jogos computacionais vêm sendo considerados como uma das principais formas de ação didática no sentido de promover o processo de ensino e aprendizagem. Salientamos que, embora outros autores utilizem a perspectiva de Tecnologias Digitais da Comunicação e Informação (TDIC), nesse trabalho, optamos por focar as discussões em termos de TIC, pois os referenciais que adotamos trabalham com essa nomenclatura.

Nessa perspectiva de intersecção entre o uso das tecnologias e o contexto do lúdico associado ao ensino de Química, torna-se necessário nos remetermos a alguns importantes conceitos buscando estabelecer nosso recorte de investigação. A palavra jogo tem seu significado oriundo do vocábulo Jacu, substantivo masculino de origem latina, que expressa gracejo, brincadeira e divertimento. Para Soares (2015) a palavra jogo é algo complexo de definir, pois trata de um conceito amplo que engloba uma série de definições. O autor argumenta que a dificuldade no significado da palavra se deve ao fato de existirem diferentes interpretações para a palavra.

Cada vez que se pronuncia a palavra jogo, várias pessoas podem entendê-la de maneiras diferentes e variadas. $\mathrm{O}$ jogo pode ser político, quando se imagina a astúcia de parlamentares ou a suas estratégias. Jogos de faz de conta, em que há forte presença do imaginário. O xadrez, o jogo de damas e o gamão, nos quais a perdedores e ganhadores, o uso de tabuleiro é também composta de estratégias e de astúcia. Manipulação de pedras e areia para passar o tempo assim como jogar pedras na água, também são particularidades do jogo (SOARES, 2015, p. 34).

A dificuldade aumenta quando se percebe que um comportamento pode ser visto como jogo ou não-jogo. Se para um observador a ação da criança indígena, que se diverte atirando com arco e flecha em pequenos animais, é um jogo ou uma brincadeira, para a comunidade indígena nada mais é que uma forma de preparo para a arte da caça necessária à subsistência da tribo. Uma mesma ação pode ser considerada jogo ou não-jogo e este fator está condicionado à cultura em que esta encontra-se inserida.

Por tantas razões fica difícil elaborar uma definição de jogo que atinja todas as diversidades de suas manifestações concretas. Kishimoto (1994), aponta três níveis de diferenciação ao termo jogo e esclarece estes aspectos diferenciadores. O primeiro refere-se ao jogo como resultado de um sistema linguístico, que funciona dentro de um contexto social. Esse aspecto considera que as línguas funcionam como fonte acessível de expressão, elas exigem o respeito a certas regras de construção. O segundo nível associa o jogo a um sistema de regras e proporciona identificar, em qualquer jogo, uma estrutura sequencial que especifica sua modalidade. São as regras que facilitam diferenciar cada jogo, ocorrendo superposição com a situação lúdica, uma vez que, quando alguém joga, está seguindo as regras do jogo e, ao mesmo tempo, desenvolvendo uma atividade lúdica. $\mathrm{O}$ último nível tem relação ao jogo como material ou objeto refere-se ao jogo enquanto objeto.

Após enfatizarmos algumas definições de jogo, destacamos uma que nos chama a atenção, definição esta trazida por Soares (2015, p.49) "jogo é qualquer atividade lúdica que tenha regras claras e explicitas, estabelecidas na sociedade, de uso comum e tradicionalmente aceitas, sejam de competição ou de cooperação". O termo atividade lúdica já é definido pelo autor como sendo "qualquer atividade prazerosa e divertida, livre e voluntária, com regras explicitas e implícitas". Soares (2015) relata que os termos jogo e atividades lúdicas são palavras indissociáveis e que a palavra jogo é sinônimo do termo atividades lúdicas. Portanto, para este 
estudo, assumiremos a postura de que jogo é tudo aquilo que é lúdico e divertido e por essa razão optamos em utilizar os dois vocábulos como sinônimos: atividades lúdicas e jogos.

Kishimoto et al. (2011) chama a atenção para o fato de que é essencial que o jogo tenha o equilíbrio entre a função lúdica e a função educativa. Sendo a função lúdica a que proporciona a diversão e o prazer, já a função educativa do jogo ensina qualquer coisa que complete o indivíduo em seu saber. Soares (2015) complementa tal aspecto explicitando que se uma destas funções se sobressai perdemos o essencial que é o equilíbrio, se a função lúdica sobressai à educativa, temos apenas o jogo, se a função educativa sobressai à função lúdica temos apenas um material didático.

Nesta perspectiva, Lima (2015) relata a construção teórica de categorias denominadas de "Dimensões Lúdicas", no qual apresenta oito dimensões lúdicas: social, cultural, educacional, imaginária, reguladora, livre/espontânea, temporal/espacial e diversão/prazer. Cada uma destas sustenta o equilíbrio entre as dimensões lúdicas, o que favorece o equilíbrio entre as funções lúdicas e educativas. Além disso, estas dimensões caracterizam os elementos essenciais que caracterizam uma atividade lúdica.

Huizinga (2007) descreve algumas características essenciais do jogo considerando o jogo como elemento da cultura.

Uma atividade livre, conscientemente tomada como 'não-séria' e exterior à vida habitual, mas ao mesmo tempo capaz de absorver o jogador de maneira intensa e total. É uma atividade desligada de todo e qualquer interesse material, com a qual não se pode obter qualquer lucro, praticada dentro de limites espaciais e temporais próprios, segundo certa ordem e certas regras (HUIZINGA, 2007, p. 16).

Diante destas características apresentadas por Huizinga (2007) e Lima (2015), e com base nas descrições realizadas pelos autores Tavares e Sousa Junior (1996), podemos resumir algumas características fundamentais do jogo:

A primeira está no fato de o jogo ser livre e ser próprio de liberdade. Ele jamais deve ser imposto pela necessidade e nunca é constituído de tarefa, sendo praticado sempre nas horas de ócio e estar ligado a noções de obrigação e dever, somente quando é constituído por uma função cultural reconhecida.

Na segunda característica, o jogo nega a vida corrente e a vida real. Trata, entretanto, de sair da vida real para uma esfera temporária de atividade, escolhendo a própria orientação. A criança sabe diferenciar o faz-de-conta da realidade. Esse fazer de conta não impede que o jogo seja realizado com seriedade e com entusiasmo. Todo jogo é capaz, a qualquer momento, de absorver inteiramente o jogador.

Como terceira característica, verifica-se o isolamento e a limitação, pois o jogo se afasta da vida comum, quanto ao lugar e à duração. Ele é jogado até o fim, considerando os limites de tempo e espaço. No momento de realização do jogo, tudo é movimento, sucessão, associação, separação.

Uma quarta característica considera o jogo como fenômeno cultural. Mesmo após o seu término, ele é conservado na memória, transmitido, podendo tornar-se tradição. A repetição pode acontecer a qualquer momento. O limite do espaço no jogo é mais evidente do que o limite do tempo. Todo jogo é realizado em um campo previamente delimitado, em cujo interior se respeitam as regras determinadas. Já na quinta e última característica, o jogo cria ordem, introduzindo no mundo imperfeito, mesmo por tempo limitado, um mundo perfeito. Exige-se, portanto, para essa perfeição uma ordem suprema e absoluta.

Este estudo culminou na elaboração das características lúdicas do jogo digital que denominaremos de "ludicidade tecnológica". A partir das análises das características lúdicas dos jogos físicos, apresentados pelos autores referenciados, foram descritas algumas características dos jogos digitais, que são as mesmas dos jogos físicos, porém em contextos diferentes. 
A primeira característica é o fato de o jogo digital ser livre, o jogador é livre para escolher por onde deseja andar dentro do jogo, pois estes apresentam um modelo de interface gráfica hierárquica, na qual tal interface tem a característica de possuir uma tela inicial, denominada tela central, onde o usuário pode passar de um ambiente para o outro, tendo apenas que voltar na tela inicial.

A segunda característica é a imaginária, que é quando o indivíduo se coloca numa situação que representa uma realidade, mas na verdade não é. Nos jogos digitais os usuários escolhem personagens, o que chamaremos de personificação, que são criados com o objetivo de retirar o usuário da vida real para uma esfera temporária de atividade lúdica.

A terceira são as regras que devem ser pré-estabelecidas, rígidas, sem espaço para negociação, nos jogos digitais estas regras são traduzidas em algoritmos de computador, sendo assim sistematicamente seguidas. Em alguns jogos digitais pode até ser possível, através de configurações, personalizar algumas regras em casos específicos, mas ainda assim tais mecanismos não são triviais e tampouco flexíveis.

A quarta característica é o espaço/tempo, pois o jogo digital poderá vir acontecer em qualquer espaço, desde que o usuário tenha em mãos um instrumento que permita o acesso ao jogo, podendo ser computadores, celulares, tabletes, entre outros. O espaço temporal também é importante, porém em jogos digitais, não se tem um tempo determinado para realizar a atividade lúdica, pois esta pode ser realizada em qualquer lugar.

Outra característica apresentada pelos jogos digitais refere-se à diversão e ao prazer proporcionado aos usuários, pois o fato de se tratar de tecnologias é algo que dá prazer aos jovens considerando-se que a faixa etária de idade escolar na educação básica é bastante ligada às novidades nos ambientes tecnológicos.

E por último, a característica educacional, pois segundo Frosi e Schlemmer (2010), é de extrema importância o uso dos jogos digitais no contexto educacional, visto que os sujeitos da aprendizagem são "nativos digitais", estão familiarizados e apreciam a interação com diferentes tipos de tecnologias digitais, incluindo os jogos.

Diante do exposto, podemos dizer que as características apresentadas nos jogos virtuais são semelhantes às apresentadas ao jogo físico. Alguns autores relatam estas semelhanças como Silva (2014) ao descrever que as atividades lúdicas digitais apresentam as mesmas características ressaltadas por pesquisadores para jogos presenciais, como prazer, diversão, interesse motivação, liberdade, dentre outros. Lima e Moita (2011) relatam que associação de jogos digitais aos conceitos químicos, favorece a aprendizagem de uma forma prazeroso e divertida, permitindo que o aluno (jogador) se torne mais ativo, ágil e crítico. Ainda segundo as autoras, a aplicação de atividades lúdicas possibilita o estimulo ao raciocínio lógico, a aquisição de conhecimento, a memória e a evolução da aprendizagem.

\section{O ensino do acerto dos coeficientes estequiométricos das reações químicas e suas dificuldades}

O balanceamento das reações químicas é uma das habilidades que devem ser adquiridas pelos alunos do Ensino Médio, sendo este, um estudo que exige dos alunos pensamento sistemático, noções de proporcionalidade dos elementos, bem como a execução de cálculos matemáticos. Neste sentido, a compreensão a respeito do acerto dos coeficientes estequiométricos das reações químicas está relacionada diretamente com a necessidade de compreender a linguagem matemática (PADILLA; GARRITZ, 2011), que são descritos pelos fundamentos da Lei de Lavoisier, lei que têm uma importância histórica na transcrição das práticas alquimistas para a prática da Química moderna (LOBEIRO et al., 2010).

Lavoisier adotou uma abordagem moderna da Química, e esta era sintetizada por sua fé na balança, que era o mais precioso aparelho de pesagem da época (STRATHERN, 2002). Para 
Lavoisier a Química nada tinha a ver com transformações misteriosas, mas que toda a mudança podia ser explicada e medida.

Em 1970 Lavoisier resolveu submeter essa aparente transformação da água em
terra a um teste exaustivo, sob as mais rigorosas condições científicas. Para isso,
usou um recipiente hermético em que a água podia ser fervida. Dentro dele, o
vapor de água entrava num tubo onde era condensado, depois a água
condensada retornava ao ponto de partida, de modo que nada era perdido no
processo. Antes de iniciar o experimento, Lavoisier pesou separadamente a
água e o recipiente. A água foi então fervida no recipiente hermético por nada
menos que 101 dias. Como antes, um sedimento apareceu no momento
esperado. Em seguida Lavoisier pesou a água, e constatou que ela pesava
precisamente o mesmo que pesara anteriormente! O sedimento não teria
podido vir da água. Quando pesou o recipiente, constatou que seu peso era
ligeiramente menor que antes - e a diferença era exatamente igual ao peso do
sedimento (STRATHERN, 2002, p. 199).

Os anos se passaram e Lavoisier com o auxílio de sua esposa Anne Marie, lançou em 1789 o Tratado Elementar de Química, no qual apresentava uma nomenclatura moderna para os elementos químicos, num total de 33 elementos, pois até o momento se usava a linguagem obscura da alquimia. Outro fato marcante nas descobertas de Lavoisier está relacionado com o processo de respiração, no qual, Lavoisier submeteu um humano a seu experimento. O sujeito era sentado em uma cadeira, despido até a cintura, pedalando uma máquina, tudo era medido, Lavoisier trabalhava com o princípio de que as substâncias que participavam da reação podiam ser transformadas, mas seu peso global permaneceria o mesmo. Essa ideia está vinculada com a lei de conservação da massa.

A Lei da conservação da massa descreve, portanto que em todas as operações da arte e da natureza, nada pode ser criado, ou seja, a quantidade de matéria existente antes da reação é a mesma depois do experimento. Neste princípio se baseia toda a arte da experimentação em Química.

Dessa forma, no estudo do balanceamento das reações químicas, os alunos devem utilizar os princípios estabelecidos pela a Lei de Lavoisier: "Uma quantidade de matéria existe antes e depois do experimento; a qualidade e a quantidade dos elementos permanecem precisamente a mesma; e nada ocorre além de mudanças e modificações na combinação desses elementos" (VIDAL; CHELONI; PORTO, 2007, p. 30).

Assim sendo, os átomos de hidrogênio numa molécula de $\mathrm{H}_{2}$ podem se combinar com os átomos de oxigênio numa molécula de $\mathrm{O}_{2}$ para formar $\mathrm{H}_{2} \mathrm{O}$, por exemplo. Mas, o número de átomos de hidrogênio e de oxigênio antes e depois da reação são conservados.

Oliveira (2012) considera o estudo do conteúdo acerto dos coeficientes estequiométricos das reações químicas, como sendo um conteúdo essencial para o entendimento de vários outros conteúdos químicos, um deles é o estudo dos cálculos estequiométricos. Yitbarek (2011), Sanger (2005) e Micklos Lewis e Bodner (2013) relatam que o estudo do conteúdo acerto dos coeficientes estequiométricos das reações químicas pelos alunos do Ensino Médio se torna mais difícil pelo fato dos alunos não possuírem um modelo mental correto do significado dos coeficientes subscritos existentes nas fórmulas químicas, bem como também não conseguem perceber a Lei de conservação da massa.

Uma das dificuldades apresentadas no processo de ensino e aprendizagem do conteúdo acerto dos coeficientes estequiométricos das reações químicas está ligado diretamente na forma como este conteúdo é abordado nas escolas de Ensino Médio. Mendes, Santana e Junior (2015) relatam que o conteúdo especifico é ensinado apenas com aulas expositivas e exercícios. Cunha (2012) descreve que, habitualmente, aprender a balancear uma equação química baseia-se em práticas que se resumem na utilização de livros didáticos, aulas expositivas no quadro negro, giz 
e a resolução de exercícios. A partir dessas perspectivas, propôs-se a elaboração de um jogo digital com foco no processo de balanceamento de equações químicas que será apresentado a seguir.

\section{METODOLOGIA}

\section{BalanceQuímico: O Processo Metodológico da Concepção, Planificação e Implementação do Software}

Para a elaboração do software educacional foi adotada a metodologia apresentada por Amante e Morgado (2001) "Concepção e Desenvolvimento de Aplicações Educativas". Atualmente existem ferramentas de programação que permitem aos professores e formadores em geral optar pelo desenvolvimento de materiais que possam facilitar o processo de ensino e aprendizagem. Amante e Morgado (2001) descrevem que para se conceber, planificar e desenvolver aplicações educativas, é necessário a passagem por algumas fases, que em um conjunto, determinam em partes a qualidade do software. Estas foram definidas, basicamente, em três grandes fases, que foram denominadas de: Concepção do Projeto; Planificação; Implementação. A Figura 2 apresentada ilustra as fases e subfases empregadas na elaboração e construção do software educacional Químico "BalanceQuímico".

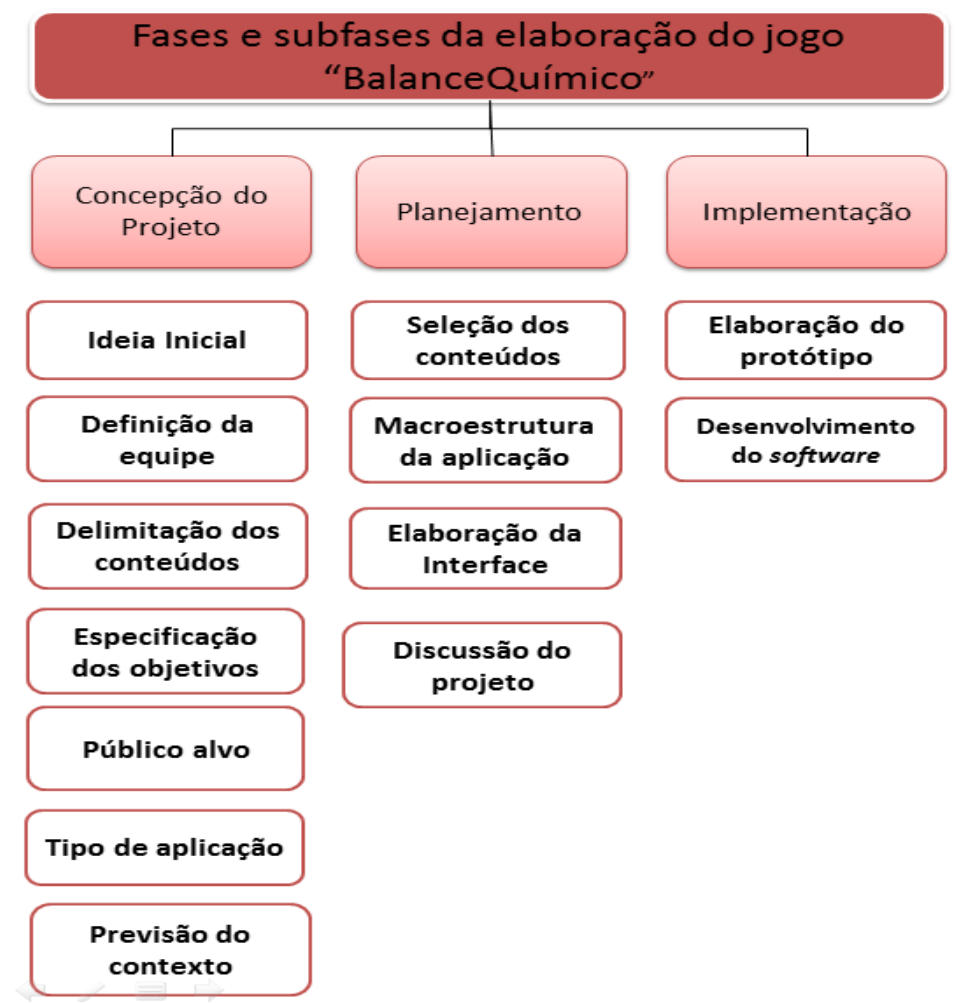

Figura 2: Fases e subfases da elaboração do jogo "BalanceQuímico". Fonte: Adaptado de Amante e Morgado (2001).

\section{Concepção do projeto}

O desenvolvimento de um software educacional requer a passagem por um conjunto de fases, que irão determinar a qualidade do produto final. A primeira subfase, no contexto do presente trabalho, foi definir a ideia inicial e o tema do trabalho. Esta primeira subfase aconteceu por meio da experiência vivida em sala de aula, como professora de Química de uma das autoras, nas conversas com os coautores e nas leituras de pesquisas bibliográficas que relatam 
dificuldades apresentadas pelos professores e alunos no processo de ensino e aprendizagem na disciplina de Química. Consequentemente, a ideia inicial foi desenvolver um jogo educacional para o ensino de Química a partir do conteúdo acerto dos coeficientes estequiométricos das reações químicas, relacionando-se o material às tecnologias. Salientamos que o conteúdo selecionado é um dos conteúdos da disciplina de Química.

A ideia inicial é a base de qualquer projeto (AMANTE; MORGADO, 2001). É de extrema importância nesta fase de elaboração do projeto questionar sobre a pertinência da aplicação educacional e analisar as possibilidades reais da sua concretização. Desta maneira, durante o início da pesquisa questionamos e pensamos sobre as possibilidades do projeto se tornar concreto e, desde o início do processo, sabíamos das dificuldades que poderíamos encontrar, pois é um desafio a elaboração de um software educacional para o ensino de Química.

Tendo em vista a ideia inicial do projeto, nos encaminhamos para a segunda subfase que foi a definição da equipe. A equipe foi formada pela autora e os coautores. No período de desenvolvimento do software educacional sempre ocorreram encontros, troca de mensagens por meios eletrônicos com os autores a fim de obter um software que possa contribuir em um diálogo produtivo entre aluno-conteúdo-professor.

A terceira subfase consiste na delimitação do conteúdo. Neste momento, já havíamos decidido que o conteúdo a ser trabalhado no software educacional seria acerto dos coeficientes estequiométricos das reações químicas, também decidimos neste momento apresentar algumas curiosidades e a relação de alguns compostos com o cotidiano, tais curiosidades podem possibilitar que os jogadores consigam aprender os conteúdos científicos relacionando-os com o cotidiano, com saberes prévios, com suas vivências, e tenham condições de interpretar melhor a Química e os fatos ocorridos em nosso cotidiano, nos quais essa Ciência se faz presente, contribuindo para formar cidadãos mais conscientes e aptos para conviverem e interagirem em sociedade.

A quarta subfase é a especificação dos objetivos pedagógicos de aplicação. Nesta subfase acontece a definição dos objetivos gerais e específicos do projeto, no sentido identificar todas as aprendizagens que procura desenvolver (AMANTE; MORGADO, 2001). O objetivo do estudo foi desenvolver um material didático que apoie o binômio ensino e aprendizagem, estimulando a criatividade e a correlação com o cotidiano.

Na próxima subfase, caracterização do público alvo. Amante e Morgado (2001) apresentam algumas questões essenciais para se caracterizar a população em que queremos trabalhar.

1. A quem se destina a aplicação?

2. Que faixa etária?

3. Quais os conhecimentos já adquiridos sobre o assunto?

4. Quais os interesses/motivações do grupo?

5. Têm, ou não, familiaridade com a utilização de computadores?

6. Que atitudes denotam face às novas tecnologias?

Definimos que o jogo se destinaria aos alunos do $2^{-}$e $3^{\circ}$ ano do Ensino Médio e que a faixa etária seria de aproximadamente 15 a 18 anos, mas lembrando que poderemos nos deparar com alunos fora desta faixa etária. Foi considerado também que o aluno terá acesso ao jogo "BalanceQuímico" após a introdução do conteúdo acerto dos coeficientes estequiométricos das reações químicas, ou para revisão já que o jogo disponibilizara uma pequena introdução sobre balanceamento Químico a partir da qual o aluno conseguirá recordar os conceitos. As três últimas questões propostas pelas autoras Amante e Morgado (2001), não foram possíveis de contemplar, pois não podemos conhecer as características de futuros usuários do jogo.

E assim, entramos na sexta subfase definição do tipo de aplicação do produto, que ficou determinado como um jogo educacional, no formato digital, para o ensino do conteúdo acerto 
dos coeficientes estequiométricos das reações químicas. Segundo Amante e Morgado (2001, p.6) "Convém desde logo concretizar o tipo de produto que se pretende desenvolver, sem prejuízo de redefinições posteriores". Nosso projeto é o desenvolvimento de software educacional para utilização em computadores e notebooks, com o foco no Balanceamento Químico. A ferramenta utilizada para o desenvolvimento do software "BalanceQuímico" foi a linguagem de programação Python pois é livre e de código aberto, sendo uma linguagem orientada a objetos, explícita e muito divertida. O jogo possibilita ao usuário participar de um ranking dos melhores jogadores entre as pessoas que jogaram, esta e uma das caraterísticas dos aspectos lúdicos envolvidos, pois Soares (2015, p.50) relata que: "jogo é tudo aquilo que é lúdico e divertido, em suas várias facetas e que, em nosso caso, será utilizado para ensinar Química”.

Por último, chegamos à subfase previsão do contexto ou contextos de utilização do programa. Neste momento, devemos definir onde o nosso objeto vai ser inserido. Ainda segundo Amante e Morgado (2001), os programas com características educacionais podem ser integrados em quatro sistemas sendo eles:

1. Contexto de ensino;

2. Contexto familiar;

3. Contexto de lazer;

4. E os diversos "contextos de saber" (bibliotecas, centros de documentação).

Nesta perspectiva, podemos afirmar que o nosso software está inserido no contexto de ensino e no lazer, pois será desenvolvido para ser utilizado nas escolas, em sala de aula ou sala de informática, e também em casa.

\section{Planejamento do Software}

Esta segunda fase consubstancia-se na elaboração da interface. Tem o objetivo de concretizar vários dos aspectos pensados na primeira fase através de um conjunto de procedimentos que conduzirão ao desenvolvimento da interface, instrumento fundamental não apenas na fase de planificação, como também em todo o processo. A segunda fase se divide em subfases:

1. Seleção e organização dos conteúdos;

2. Definição da Macroestrutura da Aplicação;

3. Elaboração da Interface;

4. Discussão do projeto e seu reajustamento.

A primeira subfase seleção e organização dos conteúdos, conforme Amante e Morgado (2001), é uma fase importante, pois as informações a incluir têm de ser cuidadosamente selecionadas. Neste momento é relevante estabelecer a quantidade de informações que o software pode comportar, quais os textos, vídeos e áudios. Nessa fase foram selecionadas todas as reações a serem utilizadas no software "BalanceQuímico" sendo que o jogo ficou dividido em 3 níveis (fácil, médio e difícil). Nos níveis fácil e médio o usuário irá responder 10 questões em cada nível, sendo elas aleatórias, pois o banco de questões possui 20 questões em cada nível, no nível difícil o usuário responderá cinco. Há um o vídeo que compõe parte da introdução ao conteúdo e também as músicas que fazem parte do software. A segunda subfase, definição da macroestrutura de aplicação, apresenta um primeiro mapa geral que clarifica a forma de se organizar a informação. Trata-se de um esboço que certamente sofrerá modificações, mas que será indispensável para definir a estrutura final da aplicação. Amante e Morgado (2001) esclarecem que a melhor maneira de mostrar a estrutura geral das informações e suas relações é o esquema mostrado na Figura 3. 


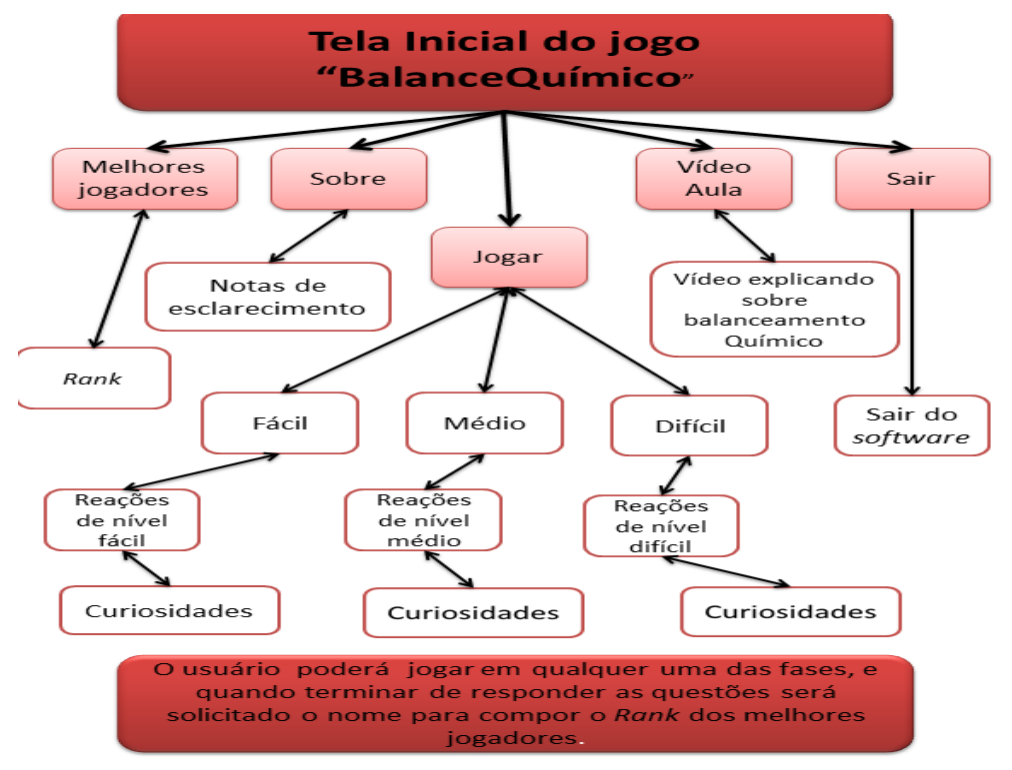

Figura 3: Esquema da Macroestrutura do jogo sobre Balanceamento Químico. Fonte: Adaptado de Amante e Morgado (2001).

E assim entramos na terceira subfase desenho de interface que "é um conjunto de elementos que proporcionam a comunicação entre o utilizador e a máquina" (AMANTE; MORGADO, 2001, p. 8). Este momento de definição da interface gráfica é muito importante, uma vez que esta é a responsável pela estrutura do ambiente de aprendizagem. A interface tem que ser criada de maneira que permita ao sujeito interagir facilmente com o computador e que também seja uma interface que motive os usuários.

Messeder Neto (2016) descreve que a motivação é uma característica fundamental quando se discute ludicidade no ensino de Química. O aluno quando se encontra motivado, envolve-se ativamente nas atividades, contribuindo no processo de ensino e aprendizagem (BZUNECK, 2009). Dessa maneira, buscamos desenvolver a interface gráfica do jogo considerando que este será usado por adolescentes, pois o conteúdo Balanceamento Químico é ministrado no 2º ano do Ensino Médio. Segundo Kishimoto (1999, p.37), "A utilização do jogo no campo do ensino e da aprendizagem proporciona condições para maximizar a construção do conhecimento, introduzindo as propriedades do lúdico, do prazer, da capacidade de iniciação e ação ativa e motivadora".

Amante e Morgado (2001) apresentam pontos importantes que devem ser considerados para a elaboração/concepção da interface gráfica:

a) Definição da estrutura e dos mecanismos básicos de navegação.

Refere-se aos "botões" a criar e que, de acordo com a estrutura definida, permitirão circular na aplicação (botões de avançar, recuar, índice, etc.). Existem fundamentalmente quatro tipos de estrutura de navegação que podem ser adaptadas: linear, hierárquica, não linear e composta (Figura 4). 


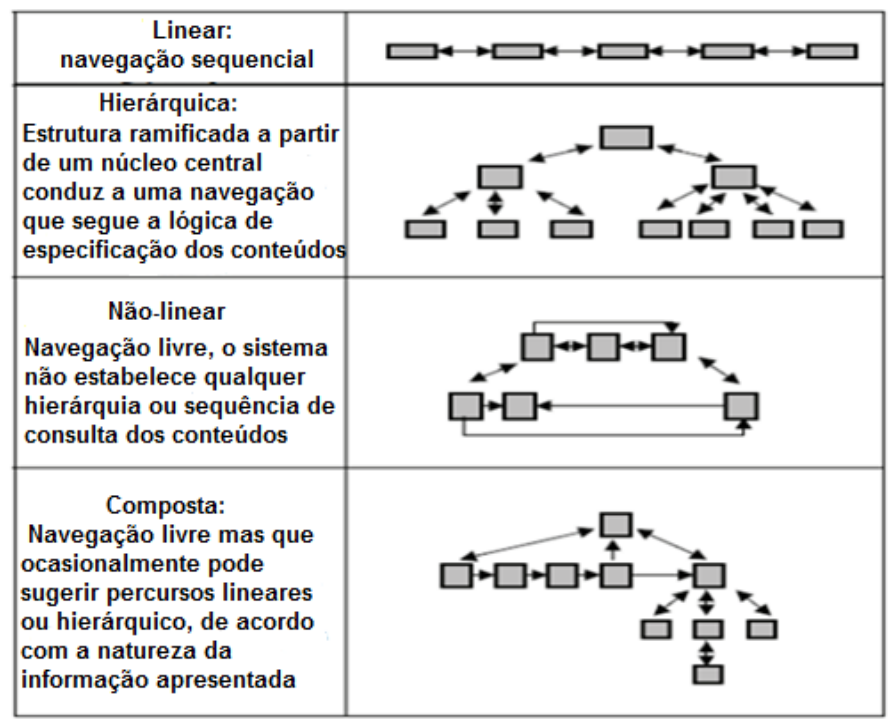

Figura 1: Tipos de navegação. Fonte: Amante e Morgado (2001, p.10).

Seguindo as definições acima, podemos classificar a interface gráfica do software "BalanceQuímico", como sendo hierárquica pois ela apresenta uma tela inicial, ou seja, um núcleo central, porém com uma navegação livre e o usuário pode passar de um ambiente para o outro, tendo apenas que voltar na tela inicial do jogo (Figura 5).

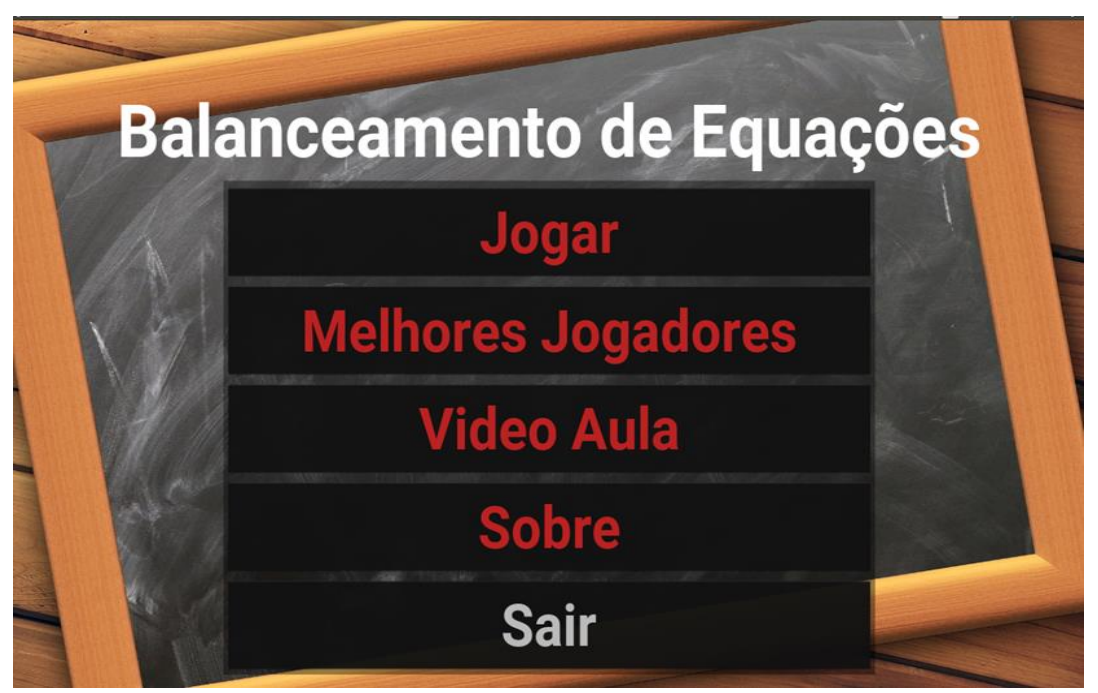

Figura 2: Tela inicial do software "BalanceQuímico". Fonte: Elaborada pelos autores.

b) Definição dos mecanismos orientadores da navegação.

Refere-se a criar instrumentos auxiliares que permitam ao usuário orientar sua consulta ou voltar ao ponto inicial do software. Este mecanismo funciona como âncora que evita que o usuário se perca, além de proporcionar uma diversificação no estilo da navegação.

No "BalanceQuímico" foi elaborado um índice geral de todos os elementos pertencentes ao software (Jogo, Melhores jogadores, Vídeo Aula, Sobre e Sair), onde também existem subíndices temáticos parciais, no índice Jogo, existem os subindices: Fácil, Médio e Difícil que irá ajudar a orientação do usuário (Figura 6). 


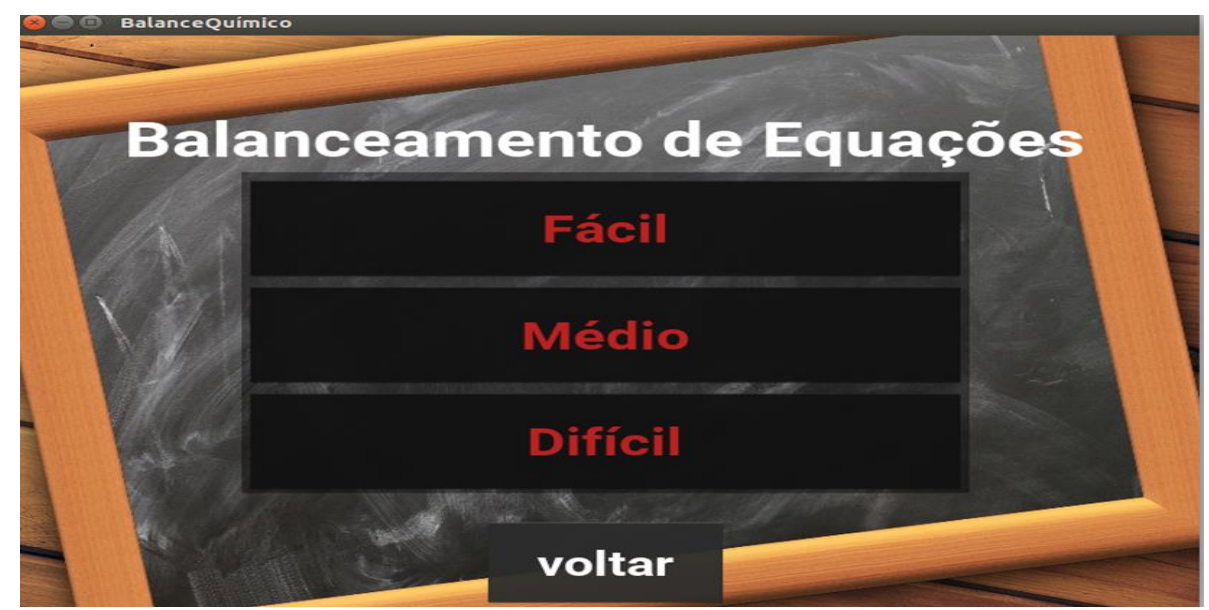

Fonte: Elaborada pelos autores.

Finalmente chegamos à última subfase discussão do projeto e seu reajustamento, esta subfase consiste em pensar em algumas reformulações, tendo como objetivo reparar alguns erros cometidos e, consequentemente, ter um produto melhor. Neste momento é importante salientar que a comunicação entre os participantes da pesquisa ocorreu constantemente.

\section{RESULTADOS E DISCUSSÕES}

\section{Implementação do software}

Esta fase de implementação do software é dividida em duas subfases que segundo as autoras Amante e Morgado (2001) são definidas como:

\section{1. $\quad$ Elaboração de um protótipo; \\ 2. Desenvolvimento da aplicação.}

A primeira subfase elaboração de um protótipo, é onde acontece o desenvolvimento dos pontos principais dos softwares, dos detalhes. Este é o momento de escolher a ferramenta de programação que será utilizada e iniciam-se as primeiras experiências e testes de tudo o que foi planejado anteriormente, este é o momento de colocar tudo em prática o que foi planejado.

Neste momento da execução do projeto, tivemos que definir as cores predominantes do software, que optamos por predomínio das cores vermelha e preta. Nesta etapa também foram definidos o tipo e o tamanho dos caracteres, que tiveram que se adaptar ao tamanho das reações, pois a cada reação apresenta quantidade de compostos diferenciados, conforme mostrado nas Figuras 7 e 8.

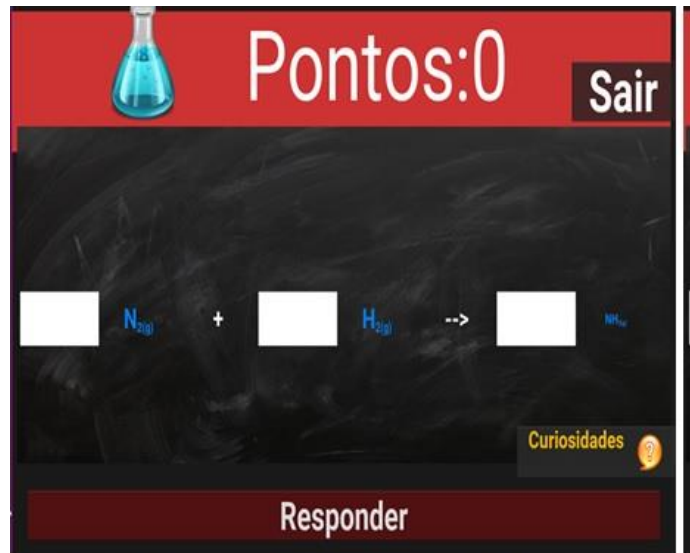

Figura 7: Tela do jogo (nivel fácil). Fonte: Elaborada pelos autores.

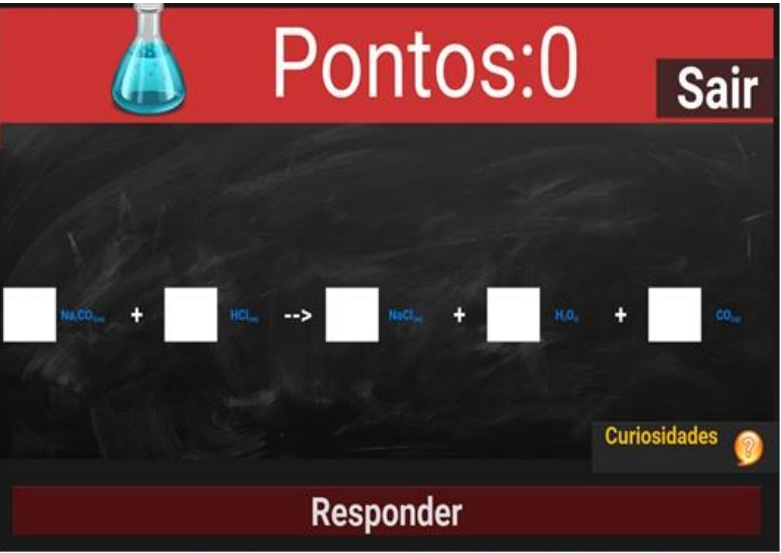

Figura 8: Tela do jogo (nivel dificil). Fonte: Elaborada pelos autores. 
A última subfase, desenvolvimento da aplicação, é a fase programação, fase de efetivar as etapas desde a ideia inicial, com recursos, instrumentos e técnicas adequadas para o desenvolvimento do software em uma versão executável. A partir dessa fase, passamos a nomear o material, de forma mais específica, como jogo. Nesta subfase, o jogo educacional passou por alguns reparos na programação para corrigir alguns defeitos do programa antes da utilização pelo usuário final. Estes testes foram realizados diversas vezes com voluntários a medida que uma nova funcionalidade era introduzida ou uma atualização era necessária. Os testes realizados foram aplicados a um tipo de sistema operacional o Linux já que este é o sistema padrão das escolas da rede Estadual de Goiás e também por ser a única plataforma com liberação de domínio público de direitos dos programas. O resultado final demonstrou que aplicação funcionou de maneira satisfatória no sistema proposto testado e foi criado um instalador para facilitar o processo, bastando apenas à execução deste e seguir os passos como a instalação de um aplicativo comum.

\section{Aplicação do jogo}

O jogo "BalanceQuímico", foi aplicado a graduandos do $7^{\mathbf{0}}$ e 8o período do curso Licenciatura em Química, aplicação ocorreu nas dependências da Universidade Estadual de Goiás, Câmpus Anápolis - Henrique Santillo, no dia 11 de abril de 2017, às 14:40 h, no laboratório de informática.

No laboratório de informática foram disponibilizados 11 computadores em que foram instalados os jogos. Os graduandos foram orientados a utilizarem o "BalanceQuímico". e foram deixados livres para utilizá-lo da maneira que quisessem. Após alguns minutos que os graduandos estavam utilizando o jogo, começaram a surgir as primeiras dúvidas. Alguns trechos representativos do diálogo entre os graduandos e a pesquisadora estão transcritos a seguir:

Graduando o1- São sempre as mesmas questões, se eu fizer novamente irei fazer as mesmas questões?

Pesquisadora - Não. O software trabalha com um banco de dados, em que nos níveis fácil tem dezenove (19) questões e o nível médio e composto de quinze (15) questões cada um e o sistema faz um sorteio aleatório, em que o usuário irá responder apenas dez (10) questões em cada nível. Já no nível difícil o banco de dados é composto de quatro (4) questões e o usuário irá responder todas as questões.

Graduando o2 - Pode ser usado números decimais ou fração?

Pesquisadora - Sim. Você pode estar utilizando números decimais, porém com uma observação, temos que colocar o ponto (.).

Observa-se, através das falas transcritas, que os graduandos mostraram interesse e motivação, como nota-se na fala dos Graduandos o1 e 02. Estes questionaram sobre aspectos técnicos da elaboração do jogo, podendo-se inferir que o jogo "BalanceQuímico", apresenta aspectos que despertam o interesse.

Cabe ressaltar da importância da participação do professor pesquisador durante a aplicação do jogo, pois conforme argumenta Rego (2014) é indispensável função do educador como um professor mediador que irá guiar e fornecer as ferramentas adequadas para promover o desenvolvimento cognitivo do seu aluno. Messeder Neto (2016) também descreve a importância do professor ajudar o estudante na elaboração do pensamento durante a realização do jogo por meio de perguntas e dicas. A presença da professora pesquisadora se fez relevante no contexto da investigação, pois esta buscou sanar dúvidas que foram surgindo durante a realização da atividade. 
Graduando o1 - Fiz uma questão e quando solicitei a resposta apareceu a seguinte mensagem "Você acertou, mas uma das regras do jogo é que você utilize o menor número inteiro possível” por quê?

Pesquisadora - Sim. Essa é uma das regras do jogo.

Graduando o1- Mas como vou saber as regras do jogo?

Pesquisadora - Na tela inicial do software "BalanceQuímico", tem vários itens, dentre eles temos um chamado SOBRE que tem todas as informações necessárias para a utilização do jogo.

Graduando o1- A minha pontuação também foi reduzida?

Pesquisadora - Sim. Quando você não cumpre a regra do jogo. Porém, se os seus índices estequiométricos estão corretos você ganha apenas a metade da pontuação, lembrando que no nível fácil cada questão você ganha 1.o ponto, no nível médio 2.0 pontos e no nível difícil 3.0 pontos quando respondido com o menor número inteiro possível.

Identificou-se que os graduandos perceberam uma das características essenciais, quando se trata de jogos, que são as regras. Segundo Lima (2015), as regras regulam a atividade e devem ser válidas e aplicáveis e o jogo deve acontecer de acordo com as regras préestabelecidas. Soares (2015) descreve que as regras devem ser de fácil entendimento, elas devem ser claras e facilmente discutíveis. É importante ressaltar que neste momento de dúvidas a respeito das regras o professor deve explicar as regras quantas vezes forem necessárias, até que fique bem claro o andamento do jogo.

Ainda segundo Soares (2015) há dois níveis de regras: as implícitas e as explícitas.

No primeiro caso (regras implícitas), elas são as limitações e possibilidades do uso de um material, decorrentes da realidade física e de lógica particular. Estas regras estão presentes em todos os materiais, jogos ou atividades. Aprendê-la não é questão de teorizar, mas de se habilitar, de empatia com o material ou com o desafio proposto. Já nas regras explícitas são as próprias limitações do material que acabam por direcioná-lo, segundo uma lógica ou rotina. Esse tipo de regra é evidente quando se trata de jogos em grupo, onde o ritual de interação entre os jogadores deve ficar claramente estabelecido. [...] as regras explícitas são as próprias regras declaradas e consensuais de um jogo, as implícitas são as habilidades mínimas necessárias para que se possa praticar um jogo em que há regras explícitas (SOARES, 2015, p.41-42).

Outros questionamentos surgiram, como apresentado abaixo:

Graduando 03 - O software está solicitando um nome, o que faço?

Pesquisadora - Digite seu nome ou um apelido, este nome irá compor o ranking dos MELHORES JOGADORES, que se encontra na tela inicial.

Graduando o3 - Vou voltar e conhecer todos os itens que compõem o jogo, depois volto a jogar novamente, pois assim vou saber de todos os detalhes do jogo. Devemos fazer sempre uma análise detalhada de qualquer software ou aplicativo que venhamos a usar com nossos alunos.

Pesquisadora - Sim realmente devemos analisar qualquer metodologia diferenciada quando tratamos em apresentá-la aos nossos alunos. Em se tratando da utilização de um software ou aplicativo existem algumas observações importantes a serem analisadas antes de apresentar aos nossos alunos.

A partir da fala do Graduando o3, percebe-se a importância do professor pesquisador estar presente durante a aplicação do jogo, pois com a explicação da pesquisadora, o graduando mostrou interesse em analisa-lo, relatando a necessidade de se conhecer o jogo antes mesmo da sua utilização com os alunos. Soares (2015) descreve essa necessidade do professor conhecer o 
jogo antes de aplicá-lo aos alunos. O autor recomenda a aplicação do jogo com amigos, ou até mesmo com os alunos, desde que esclareça que é um teste para o desenvolvimento de um jogo para o conteúdo específico.

\section{CONCLUSÃO}

Compreendemos que nos arriscamos em caminhos desconhecidos, confiamos no trabalho em equipe e aceitamos o desafio de refletir sobre o processo de ensino e aprendizagem de acerto dos coeficientes estequiométricos das reações químicas mediado pelas tecnologias ao desenvolvermos o jogo BalanceQuímico. Concebemos, planificamos e implementamos o software "BalanceQuímico". Encontramos desafios no caminho percorrido, pois tivemos alguns obstáculos na programação que não conseguíamos resolver, fazendo com que várias vezes trocássemos o caminho.

O desenvolvimento de um software educacional voltado para o ensino e aprendizagem de Química requer a integração de diversas áreas de conhecimentos como programação, Química, educação e o processo de ensino e aprendizagem. É um processo complexo, pois um software educacional precisa contemplar questões especificas do conhecimento, ou seja, o conteúdo químico acerto dos coeficientes estequiométricos das reações químicas, além do estabelecimento de diálogo entre os conhecimentos de informática e fundamentos pedagógicos. Com a integração destas áreas de conhecimento podemos elaborar e desenvolver um software adequado ao binômio ensino e aprendizagem.

Neste artigo apresentamos as etapas de desenvolvimento de softwares para o ensino de Química, como também sua aplicação, no formato de um jogo, aos graduandos do curso Licenciatura em Química da Universidade Estadual de Goiás. Compreendemos que o conhecimento que o professor de química tem sobre a sala de aula e sobre as dificuldades dos alunos em relação ao entendimento dos conceitos mostra-se importante para a criação e materiais didáticos, sejam tecnológicos ou não. Neste caso específico, a criação do jogo mobilizou conhecimentos que, para além de conceitos químicos, envolveram saberes relacionados à informática, às questões educacionais como os caminhos de construção do conhecimento e ao contexto da ludicidade, pois o jogo em ambiente digital tem características lúdicas importantes que contribuem com a apropriação conceitual do objeto pelos sujeitos.

Na perspectiva dos graduandos, o jogo desenvolvido "BalanceQuímico" é um elemento que apresenta relevante contribuição para o processo de ensino e aprendizagem de Química, mais especificamente do conteúdo acerto dos coeficientes estequiométricos das reações químicas, pois o jogo desenvolvido pode contribuir tanto para a aproximação entre a sala de aula e os aspectos lúdicos, quanto para a aproximação entre a mesma sala de aula e os elementos da tecnologia que, nesse caso, são representados pelo jogo digital. Os professores em formação destacaram a importância de o professor conhecer estes materiais ao utilizá-los em ambiente escolar. Dessa forma, não podemos deixar de ressaltar o papel do professor na utilização de jogos digitais tendo em vista tanto seu conhecimento prévio sobre os conceitos abordados no jogo quanto sobre os detalhes específicos inerentes ao uso da atividade lúdica.

\section{REFERÊNCIAS}

AMANTE, L.; MORGADO, L. Metodologia de concepção e desenvolvimento de aplicações educativas: o caso dos materiais hipermídia. Discursos: Língua, cultura e sociedade, S.3, n. especial, p. 27-43, 2001.

AULER, D.; DELIZOICOV, D. Ciência-tecnologia-sociedade: relações estabelecidas por professores de ciências. Revista Electrónica de Enseñanza de las Ciencias, V.5, n.2, p. 337-355, 2006. 
BZUNECK, J. A. A Motivação do aluno: aspectos introdutórios. In: BORUCHOVITCH, E.; BZUNECK, J.

A. (orgs.). A Motivação do Aluno: Contribuições da psicologia contemporânea. 4. ed. Petrópolis: Vozes, 2009. 183 p.

CARRAHER, D.W. O Papel do Computador na Aprendizagem. Acesso, v.3, n.5, p.19-21, 1992.

CUNHA, M.B. Jogos no Ensino de Química: Considerações Teóricas para sua Utilização em Sala de Aula, Química Nova na Escola, v.34, n.2, p.92-98, 2012.

FROSI, F.; SCHLEMMER, E. Jogos Digitais no Contexto Escolar: desafios e possibilidades para a Prática Docente. IX SBGames - Florianópolis - SC, 8 a 10 de novembro de 2010. Disponível em: <http://www.bndes.gov.br/SiteBNDES/bndes/bndes_pt/Galerias/Arquivos/conhecime nto/seminario/seminario_mapeamento_industria_gameso42014_RelApoioCensoIndu striaBrasileiradeJogos.pdf $>$. Acessado em: 25 out. 2017.

GIORDAN, M. Computadores e Linguagens nas Aulas de Ciências: uma Perspectiva Sociocultural para Compreender a Construção de Significados. Ijuí: Unijuí, 2013. 328 p.

HUIZINGA, J. Homo Ludens: o jogo como elemento da cultura. 5. ed. São Paulo: Perspectiva, 2007. 243 p.

KISHIMOTO, T. M. O jogo e a Educação Infantil. São Paulo: Pioneira Thomson Learning, 1994. 62 p. , T. M. (Org.). Jogo, Brinquedo, Brincadeira e a Educação. São Paulo: Cortez, 1999. 207

p.

KISHIMOTO, T. M. et al. Jogo e letramento: crianças de 6 anos no ensino fundamental. Educação e Pesquisa, v. 37, n. 1, p. 191-210, 2011.

LIMA, E. C. C. Concepção, Construção e Aplicação de Atividades Lúdicas por Licenciados da Área de Ensino de Ciências. 2015. 156 f. Dissertação (Mestrado em Ensino, História e Filosofia das Ciências e Matemática) - Universidade Federal do ABC, Santo André. 2015.

LIMA, É. R. P. O.; MOITA, F. M. G. S. A Tecnologia e o Ensino de Química: Jogos Digitais como Interface Metodológica. Campina Grande: EDUEPB, 2011, p. 131-154.

LOBEIRO, A.M. et al. Aplicação do Software Maple 12 para o balanceamento de equações químicas. In: Símposio Nacional de ensino de Ciências e Tecnologias, 2., 2010, Paraná. Anais... Paraná: UTFPR, 2010. Disponível em: < http://www.sinect.com.br/anais2010/artigos/EQ/204.pdf >.Acesso em: 10 nov. 2017.

MEDEIROS, M. A. Avaliação do conhecimento sobre periodicidade química em uma turma de química geral do ensino a distância. Revista Química Nova, v.36, n. 3, p.474-479, 2013.

MENDES, A. P.; SANTANA, G. P.; JÚNIOR, E. S. F. P. O uso do software PhEt como ferramenta para o ensino de balanceamento de reação química. Revista Areté, Manaus, v.8, n.16, p. 52-6o, 2015.

MESSEDER NETO, H. S. O Lúdico no Ensino de Química na Perspectiva Histórico-Cultural. Além do Espetáculo, Além da Aparência. Curitiba: Prismas, 2016. 234 p.

MICKLOS LEWIS, A. L.; BODNER, G. M. Chemical reactions: what understanding do students with blindness develop? Chemistry Education Research and Practice, v.14, n.4, p. 625, 2013.

NUNES, S.C.; SANTOS, R.P. O Construcionismo de Papert na criação de um objeto de aprendizagem e sua avaliação segundo a taxionomia de Bloom. Trabalho apresentado no IX Encontro Nacional de Pesquisa em Educação em Ciências. Anais... Águas de Lindóia, 2013. Disponível em: <http://www.fisicainteressante.com/files/artigo-construcionismo_papert_objeto_de_aprendizagem.pdf>. Acesso em: 10 nov. 2017.

OLIVEIRA, R.C. Uso de modelos moleculares por alunos de Ensino Médio: contribuições para o desenvolvimento de modelos mentais de conceitos químicos.2012. 238 f. Tese (Doutorado em Química) Universidade Federal de São Carlos, 2012.

PADILLA, K.; GARRITZ, A. The pedagogical content knowledge of university chemistry Narst 2011 Annual Meet. Anais...2011 
REGO, T. C. Vygotsky: uma perspectiva histórico-cultural da educação. 25. ed. Petrópolis: Vozes, 2014. $139 \mathrm{p}$.

SANGER, M. J. Evaluating Students' Conceptual Understanding of Balanced Equations and Stoichiometric Ratios Using a Particulate Drawing. Journal of Chemical Education, v.82, n.1, p. 131, 2005 .

SILVA, E. A. SisMol3D: Desenvolvimento de um Software Educacional para o Ensino de Estruturas Moleculares em Química. 2014. 75 f. Dissertação (Mestrado em Ciência e Tecnologia para Recursos Amazônicos) - Universidade Federal do Amazonas, Itacoatiara. 2014.

SOARES, M. H. F. B. Jogos e Atividades lúdicas para o Ensino de Química. 2. ed. Goiânia: Kelps, 2015. 198 p.

SOUZA, M. P. et al. Titulando 2004: um software para o Ensino de Química. Química Nova na Escola. V. 22, p.35-37, 2005.

STRATHERN, P. O sonho de Mendeleiev: a verdadeira história da química. Rio de Janeiro: Jorge Zahar Ed., 2002. 264p.

TAVARES, M.; SOUZA JÚNIOR, M. O jogo como conteúdo de ensino para a prática pedagógica da educação física na escola. Revista Corporis, v.1, p. 1-6, 1996.

VIDAL, P. H. O.; CHELONI, F. O.; PORTO, P. A. O Lavoisier que não está presente nos livros didáticos, Química Nova na Escola, n.26, p. 29-32, 2007.

YITBAREK, S. Chemical reaction: Diagnosis and towards remedy of misconceptions. AJCE, v.1, January, p. 10-28, 2011.

GISLANE SILVÉRIO NETO BARRETO: Mestre em Ensino de Ciências pela Universidade Estadual de Goiás; Especialista em Docência Universitária pela Faculdade Católica de Anápolis;

Graduada em Licenciatura Química pela Universidade Estadual de Goiás; Professora de Química da Educação Básica na Secretaria de Educação, Cultura e Esporte de Goiás (SEDUCE).

E-mail: gislane.silverio@gmail.com

JANAÍNA LOPES XAVIER: Mestranda no Programa de Pós-Graduação em Ensino de Ciências da

Universidade Estadual de Goiás; Especialista em Educação para a Diversidade e Cidadania pela Universidade Federal de Goiás; Licenciada em Química pela Universidade Estadual de Goiás; Professora de Química da Educação Básica na Secretaria de Educação, Cultura e Esporte de Goiás (SEDUCE).

E-mail: janainalx@gmail.com

JOSÉ DIVINO DOS SANTOS: Licenciado em Química pela Universidade Federal de Goiás. Mestre em Química pela Universidade Federal de São Carlos. Doutor em Química pela Universidade Federal de São Carlos. Docente da Universidade Estadual de Goiás atuando também no Programa de Pós-Graduação em Ensino de Ciências da Universidade Estadual de Goiás desenvolvendo pesquisas nas áreas Química Teórica em sensores, varistores, sensores de gases, catalise, nanotecnologia, programação em Shell, modelagem molecular de polímeros e interações macromoléculas utilizando a dinâmica molecular com aproximação clássica e quântica. Também atua na orientação em pós-graduação nas temáticas que envolvem construção de softwares aplicados ao ensino de Ciências com linguagens de programação como Python, Java, C, PHP, awk, bash, entre outras.

E-mail: jdsantosdivino@gmail.com

NYUARA ARAÚJO DA SILVA MESQUITA: Bacharel, licenciada, mestre e doutora em Química pela Universidade Federal de Goiás. Docente do Instituto de Química da Universidade Federal de Goiás. Orienta no mestrado e doutorado no Programa de Pós-Graduação em Química da Universidade Federal de Goiás e no Programa de PósGraduação em Educação em Ciências e Matemática da Universidade Federal de Goiás. Trabalha temas que envolvem tecnologias no ensino de Ciências, atividades lúdicas no ensino de Química, políticas públicas no ensino de Química e Educação Ambiental.

E-mail: nyuara2006@gmail.com 